\title{
COMPARISON OF SEQUESTRECTOMY AND AGGRESSIVE DISCECTOMIES IN TERMS OF RECURRENCE IN LUMBAR DISC HERNIA SURGERIES
}

\author{
(1) Faruk ALTINEL ${ }^{1}$, (1) Fikret ȘAHINTÜRK², (1) Yonca PEKCAN³ \\ ${ }^{1}$ Başkent University, Zübeyde Hanım Training and Research Hospital, Clinic of Neurosurgery, İzmir, Turkey \\ ${ }^{2}$ Başkent University Faculty of Medicine, Department of Neurosurgery, Ankara, Turkey \\ ${ }^{3}$ Başkent University, Zübeyde Hanım Training and Research Hospital, Clinic of Anaesthesiology and Reanimation, Izmir, Turkey
}

Objective: Lumbar disc herniation (LDH) is a disease that seriously affects people's social and work life. LDH recurrence is a condition that occurs after lumbar microdiscectomy and is characterised by findings of failed lumbar surgery syndrome. Recurrent disk herniation may develop due to demographic factors, obesity and limited discectomy. Therefore, this study aimed to compare the recurrent disk herniations that develop following aggressive discectomy (AD) and sequestrectomy.

Materials and Methods: Seventy patients diagnosed with extruded LDH at a single level who underwent sequestrectomy (S) and 70 patients with the same diagnosis who underwent AD at Başkent University Zübeyde Hanım Hospital were enrolled in this study. In the study groups, age, gender, comorbidity characteristics, disk herniation level, duration of surgery, blood loss, hospitalisation duration and complications including recurrence rate, reoperation rate, low back pain postoperatively and visual analogue scale for radicular pain during the last evaluation and analgesic application results were collected in addition to the perioperative information.

Results: In the comparison S and AD, recurrence (62.50\%) and reoperation rates (57.10\%) were found to be higher in patients who underwent sequestrectomy. Although surgical site infection (50.00\%) occurred at the same proportion in both groups, the rate of dural tear (66.70\%) was found to be higher in those who underwent sequestrectomy.

Conclusion: Although several noninvasive procedures have been defined as an alternative to microsurgery, surgical discectomy remains an effective treatment method for $L D H$. We suggest that for cases of $L D H$ recurrence, $A D$ is more preferred over other surgical methods.

Keywords: Seguestrectomy, aggressive discectomy, disc herniation

\section{INTRODUCTION}

In lumbar disc surgery, less invasive interventions have been developed since Mixter and Barr ${ }^{(1)}$ completed the first successful lumbar herniated disc resection, including extensive laminectomy, in 1934. Two procedures have been discussed since microsurgery (MC) became the gold standard for lumbar disc herniation (LDH). One of these procedures involves resection of the herniated disc fragment from the spinal canal and aggressive curettage of the normal disc ${ }^{(2)}$. Disc distance curettage leads to intervertebral instability and disc height collapse, thus contributing to the "failed lumbar surgery syndrome"(3). The other procedure is sequestrectomy alone with disc fragment resection from the spinal canal. This intervention is thought to maintain disc height and minimise intervertebral instability ${ }^{(4,5)}$. Both interventions are widely used in clinical practice. Therefore, this study aimed to describe the clinical and preoperative results and complication and reherniation rates in patients operated by different surgeons in two separate hospitals with a review of the literature.

\section{MATERIALS AND METHODS}

\section{Participants}

Perioperative information including age, gender, magnetic resonance imaging (MRI) and diagnosis, level rates, surgery duration, intraoperative blood loss, hospitalisation duration, complications and results including recurrence rates, reoperation rates, low back pain, visual analogue scale (VAS) for sciatica pain at the time of the final evaluation and analgesic use postoperatively were collected from patient files and by 
phone follow-up. A total of 140 patients diagnosed with LDH at a single level on the caudal and cranial vertebrae or with extruded LDH on the disc level in lumbar MRI were divided into two groups and studied retrospectively.

Group A: Underwent sequestrectomy

Group B: Underwent aggressive discectomy (AD)

Patients aged 20-75 years with a single-level extruded disc between L1 and S1 in an MRI were included in the study. Patients with two or more extruded discs or spondylolisthesis were excluded.

\section{Surgical Technique}

Surgical treatment was performed under general anaesthesia and with the use of a surgical microscope. In group A patients, only sequestered fragments on the disc level with caudal and cranial migration were resected. A ruptured posterior longitudinal ligament and annulus fibrosus were observed. In group B patients, sequestered fragments were resected, and disc fragments located at the intervertebral distance were resected through the "+"-shaped incision made in the annulus. The disc distance was cleaned until the anterior longitudinal ligament was observed in front of the distance and the amount of resected disc was measured. Patients were discharged on the first postoperative day and resumed their daily activities in the $3^{\text {rd }}$ postoperative week without corset use and movement restrictions.

\section{Statistictical Analysis}

Statistical analysis was done using SPSS 25 (IBM Corp. Released 2017. IBM SPSS Statistics for Windows, Version 25.0. Armonk, NY: IBM Corp.) statistical package programme. Variables were expressed as mean \pm standard deviation, percentage and frequency values. Variables were analysed after checking for normality and homogeneity of variance preconditions (using the Shapiro-Wilk and Levene test). During the data analysis, Independent 2 group $t$ test (Student's $t$-test) was used to compare the two groups, and Mann-Whitney $U$ test was used when prerequisites were not met. Categorical data were analysed using the Fisher's exact test and chi-square test. In cases where expected frequencies were $<20 \%$, analysis was done using the "Monte Carlo Simulation Method" to include these frequencies in the analysis. For the significance level of the tests, $p<0.05$ and $p<0.01$ values were accepted.

\section{RESULTS}

\section{Preoperative Neurological Results}

In the preoperative period, particularly during the 2-year follow-up period, patients presented to the outpatient clinic with pain similar to sciatalgia that radiates to the right and left lower limbs, weakness on foot dorsoflexion or weakness in the toes and muscle atrophy (Table 1). The American Society of Anaesthesiologists (ASA) classification results for preoperative anaesthesia assessment were $100 \%$ ASA (1) in group A and 93.8\% ASA (1) and 6.2\% ASA (2) in group B.

\section{Preoperative Lumbar MRI Results}

In the lumbar MRI of group A patients, extruded disc was detected on the left L3/L4 (60\%), L4/L5 (59.50\%) and L5/S1 (60.00\%) levels and on the right L4/L5 (65.90\%) and right L5/ S1 (53.60\%) levels in group B patients. A statistically significant difference was observed between right $L 3 / L 4$, right $L 4 / L 5$ and right $L 5 / S 1$ extrusion categories in patients who underwent limited and ADs ( $p=0.003$ ) (Table 1).

\section{Postoperative Back and Leg Pain and Analgesic Use}

In this study, symptom relief and patient satisfaction were also analysed. Although postoperative VAS results indicating low back and leg pains were found to be lower in patients who underwent sequestrectomy $(66.70 \%)$ and moderate in those who underwent $A D$, no significant statistical difference was observed between the two groups ( $p=0,819)$. In addition, the frequency of postoperative analgesic use in the sequestrectomy group was significantly lower in both the short-term $(<1$ year) and long-term (>1 year) follow-ups (48.00\%) (Table 2 ). Therefore, better functional recovery and satisfaction occurred in the sequestrectomy group.

\section{Recurrence Results}

All patients were followed-up for 24 months. Recurrence was reported in 16 of 140 patients, including 10 group A patients $(14,28 \%)$ and six group B patients (8,57\%). In this study, recurrence rates were higher in the sequestrectomy group $(p=0.288)$ (Table 3).

\section{Reoperation Results}

With regard to the follow-up of the patients using MRI, one group A patient had recurrence in the first 6 months, four in the 1-2-year follow-up, one in the 2-3-year follow-up and 2 after the 3-year follow-up; all of them were reoperated and two patients recovered by responding to a conservative treatment. Conversely, in group B, recurrence occurred in one patient at one month (during the first 10 days), one in 6-12 months, one in 2 years and three after 3 years; all of them were also reoperated. Regarding the follow-up of both groups, recurrence was more frequently observed in the 1-2 years postoperative in group A patients, but either as early as 10 days postoperative or after 3 years in group B patients. While infection was equally observed in both groups, dural tear was higher in group A (66.70\%) (Table 3).

\section{Peroperative Results}

Although no difference was observed in intraoperative blood, the duration of surgery and length of hospitalisation between group A and B patients, a statistically significant difference was observed in the disc amount $(p=0.001)$ and follow-up time $(p=0.040)$ variables between patients who underwent sequestrectomy and $\mathrm{AD}$ (Table 4). 
Table 1. Demographic, clinical and MRI results of patients with limited and aggressive discectomy

\begin{tabular}{|c|c|c|c|c|c|c|}
\hline \multicolumn{3}{|l|}{ Preoperative } & \multirow{2}{*}{$\begin{array}{l}\text { Sequestrectomy } \\
50.2 \pm 16.39\end{array}$} & \multirow{2}{*}{$\begin{array}{l}\begin{array}{l}\text { Aggressive } \\
\text { discectomy }\end{array} \\
50.44 \pm 12.07\end{array}$} & \multirow{2}{*}{$\begin{array}{l}\text { Total } \\
-\end{array}$} & \multirow{2}{*}{$\begin{array}{l}p \\
0.920\end{array}$} \\
\hline Age & & & & & & \\
\hline \multirow{4}{*}{ Sex } & \multirow{2}{*}{$\mathrm{F}$} & $\mathrm{n}$ & 36 & 37 & 73 & \multirow{4}{*}{0.866} \\
\hline & & $\%$ & $49.30 \%$ & $50.70 \%$ & $100.00 \%$ & \\
\hline & \multirow{2}{*}{ M } & $\mathrm{n}$ & 34 & 33 & 67 & \\
\hline & & $\%$ & $50.70 \%$ & $49.30 \%$ & $100.00 \%$ & \\
\hline \multirow{14}{*}{ Symptom } & \multirow{2}{*}{ R muscle hypotonia } & $\mathrm{n}$ & 1 & 0 & 1 & \multirow{14}{*}{0.526} \\
\hline & & $\%$ & $100.00 \%$ & $0.00 \%$ & $100.00 \%$ & \\
\hline & \multirow{2}{*}{ L muscle weakness } & $\mathrm{n}$ & 9 & 14 & 23 & \\
\hline & & $\%$ & $39.10 \%$ & $60.90 \%$ & $100.00 \%$ & \\
\hline & \multirow{2}{*}{ R muscle weakness } & $\mathrm{n}$ & 8 & 11 & 19 & \\
\hline & & $\%$ & $42.10 \%$ & $57.90 \%$ & $100.00 \%$ & \\
\hline & \multirow{2}{*}{ R muscle atrophy } & $n$ & 2 & 1 & 3 & \\
\hline & & $\%$ & $66.70 \%$ & $33.30 \%$ & $100.00 \%$ & \\
\hline & \multirow{2}{*}{ R sciatalgia } & $\mathrm{n}$ & 25 & 28 & 53 & \\
\hline & & $\%$ & $47.20 \%$ & $52.80 \%$ & $100.00 \%$ & \\
\hline & \multirow{2}{*}{ L muscle atrophy } & $\mathrm{n}$ & 1 & 1 & 2 & \\
\hline & & $\%$ & $50.00 \%$ & $50.00 \%$ & $100.00 \%$ & \\
\hline & \multirow{2}{*}{ L sciatalgia } & $\mathrm{n}$ & 24 & 15 & 39 & \\
\hline & & $\%$ & $61.50 \%$ & $38.50 \%$ & $100.00 \%$ & \\
\hline \multirow{16}{*}{ Lumbar MRI } & \multirow{2}{*}{ L L2/3 extrusion } & $\mathrm{n}$ & 2 & 2 & 4 & \multirow{16}{*}{0.03} \\
\hline & & $\%$ & $50.00 \%$ & $50.00 \%$ & $100.00 \%$ & \\
\hline & \multirow{2}{*}{ L L3/4 extrusion } & $\mathrm{n}$ & 3 & 2 & 5 & \\
\hline & & $\%$ & $60.00 \%$ & $40.00 \%$ & $100.00 \%$ & \\
\hline & \multirow{2}{*}{ L L4/5 extrusion } & $\mathrm{n}$ & 22 & 15 & 37 & \\
\hline & & $\%$ & $59.50 \%$ & $40.50 \%$ & $100.00 \%$ & \\
\hline & \multirow{2}{*}{ L L5/S1 extrusion } & $\mathrm{n}$ & 9 & 6 & 15 & \\
\hline & & $\%$ & $60.00 \%$ & $40.00 \%$ & $100.00 \%$ & \\
\hline & \multirow{2}{*}{ R L2/3 extrusion } & $\mathrm{n}$ & 1 & 1 & 2 & \\
\hline & & $\%$ & $50.00 \%$ & $50.00 \%$ & $100.00 \%$ & \\
\hline & \multirow{2}{*}{ R L3/4 extrusion } & $\mathrm{n}$ & 6 & 2 & 8 & \\
\hline & & $\%$ & $75.00 \%$ & $25.00 \%$ & $100.00 \%$ & \\
\hline & \multirow{2}{*}{ R L4/5 extrusion } & $\mathrm{n}$ & 14 & 27 & 41 & \\
\hline & & $\%$ & $34.10 \%$ & $65.90 \%$ & $100.00 \%$ & \\
\hline & \multirow{2}{*}{$\begin{array}{l}\mathrm{R} L 5 / \mathrm{S} 1 \\
\text { extrusion }\end{array}$} & $\mathrm{n}$ & 13 & 15 & 28 & \\
\hline & & $\%$ & $46.40 \%$ & $53.60 \%$ & $100.00 \%$ & \\
\hline
\end{tabular}

MRI: Magnetic resonance imaging, F: Female, M: Male, L: Left, R: Right, n: Number

\section{DISCUSSION}

LDH is a disease characterised by low back pain radiating to the legs and sensory and motor deficits. Its incidence was reported to be $1-2 \%$ in the general population and 4.86 per 1,000 person-years in the younger population ${ }^{(6-8)}$. This study aimed to determine the role of the surgical technique used in the first discectomy in the reduction of the recurrence risk. Recurrence is one of the common complications occurring after lumbar discectomy. Although several procedures may increase the recurrence risk, a high risk of recurrence has been observed after a limited disc resection and the disc degeneration risk increases after an aggressive disc resection ${ }^{(8-10)}$. 
Table 2. Preoperative and postoperative results of patients with limited and aggressive discectomy

\begin{tabular}{|c|c|c|c|c|c|c|}
\hline \multicolumn{3}{|c|}{$\begin{array}{l}\text { Sequestrectomy } \\
\text { Aggressive discectomy }\end{array}$} & \multicolumn{2}{|c|}{ Group } & \multirow{2}{*}{$\begin{array}{l}\text { Total } \\
107\end{array}$} & \multirow[t]{2}{*}{$p$} \\
\hline \multirow{6}{*}{ ASA } & \multirow{2}{*}{$0.06-0.08$} & $\mathrm{n}$ & 53 & 54 & & \\
\hline & & $\%$ & $49.50 \%$ & $50.50 \%$ & $100.00 \%$ & \multirow{5}{*}{0.17} \\
\hline & \multirow{2}{*}{$0.27-0.4$} & $\mathrm{n}$ & 17 & 13 & 30 & \\
\hline & & $\%$ & $56.70 \%$ & $43.30 \%$ & $100.00 \%$ & \\
\hline & \multirow{2}{*}{$1.8-4.3$} & $\mathrm{n}$ & 0 & 3 & 3 & \\
\hline & & $\%$ & $0.00 \%$ & $100.00 \%$ & $100.00 \%$ & \\
\hline \multirow{12}{*}{ Postop VAS } & \multirow{2}{*}{0} & $\mathrm{n}$ & 52 & 54 & 106 & \multirow{12}{*}{0.819} \\
\hline & & $\%$ & $49.10 \%$ & $50.90 \%$ & $100.00 \%$ & \\
\hline & \multirow[b]{2}{*}{1} & $\mathrm{n}$ & 6 & 3 & 9 & \\
\hline & & $\%$ & $66.70 \%$ & $33.30 \%$ & $100.00 \%$ & \\
\hline & \multirow{2}{*}{2} & $\mathrm{n}$ & 5 & 4 & 9 & \\
\hline & & $\%$ & $55.60 \%$ & $44.40 \%$ & $100.00 \%$ & \\
\hline & \multirow{2}{*}{3} & $\mathrm{n}$ & 2 & 4 & 6 & \\
\hline & & $\%$ & $33.30 \%$ & $66.70 \%$ & $100.00 \%$ & \\
\hline & \multirow{2}{*}{4} & $\mathrm{n}$ & 2 & 3 & 5 & \\
\hline & & $\%$ & $40.00 \%$ & $60.00 \%$ & $100.00 \%$ & \\
\hline & \multirow{2}{*}{5} & $\mathrm{n}$ & 3 & 2 & 5 & \\
\hline & & $\%$ & $60.00 \%$ & $40.00 \%$ & $100.00 \%$ & \\
\hline \multirow{12}{*}{ Postop analgesia } & \multirow{2}{*}{0} & $\mathrm{n}$ & 48 & 52 & 100 & \multirow{12}{*}{0.523} \\
\hline & & $\%$ & $48.00 \%$ & $52.00 \%$ & $100.00 \%$ & \\
\hline & \multirow{2}{*}{1} & $\mathrm{n}$ & 7 & 5 & 12 & \\
\hline & & $\%$ & $58.30 \%$ & $41.70 \%$ & $100.00 \%$ & \\
\hline & \multirow{2}{*}{2} & $\mathrm{n}$ & 6 & 6 & 12 & \\
\hline & & $\%$ & $50.00 \%$ & $50.00 \%$ & $100.00 \%$ & \\
\hline & \multirow{2}{*}{3} & $\mathrm{n}$ & 8 & 5 & 13 & \\
\hline & & $\%$ & $61.50 \%$ & $38.50 \%$ & $100.00 \%$ & \\
\hline & \multirow{2}{*}{4} & $\mathrm{n}$ & 0 & 2 & 2 & \\
\hline & & $\%$ & $0.00 \%$ & $100.00 \%$ & $100.00 \%$ & \\
\hline & \multirow{2}{*}{5} & $\mathrm{n}$ & 1 & 0 & 1 & \\
\hline & & $\%$ & $100.00 \%$ & $0.00 \%$ & $100.00 \%$ & \\
\hline
\end{tabular}

ASA: The American Society of Anaesthesiologists, Postop: Postoperative, VAS: Visual analogue scale, n: Number

The symptomatic recurrence rate was $4 \%$ in all series, and the reoperation rate was $6.4 \%$ in the first year, which increased by $10 \%$ after the first year ${ }^{(11)}$. In this context, in a recent meta-analysis, aggressive disc resection, large annulotomy and curettage of the disc interspace (AD) were compared with a more conservative resection of the disc fragment (sequestrectomy), and the recurrence incidence was reported to be higher in the sequestrectomy group than in the aggressive technique group ${ }^{(12,13)}$.

Results of 12 previous studies showed that when $A D$ and sequestrectomy were compared, shorter surgical duration, lower postoperative VAS, lesser postoperative analgesic administration and higher satisfaction rates were reported. However, the recurrence rate, complication rate, reoperation rate and intraoperative blood loss were reported as being equivalent for both methods ${ }^{(13)}$. Although publications before 2009 showed that the recurrence rate is higher after sequestrectomy, Ran et al. ${ }^{(13)}$ and Fakouri et al. ${ }^{(14)}$ reported that the recurrence rate was equal after both discectomy and sequestrectomy. In our study, when comparing both groups, the recurrence rate was found to be higher (62.50\%) after sequestrectomy; however, the difference was not statistically significant $(\mathrm{p}=0.28)$.

Additionally, annulus fibrosus openness should be considered in lumbar disc surgery, because patients with small annulus defects during surgery and free disc in the spinal canal are suitable for sequestrectomy. Recurrence rate has been reported to be lower in patients with $<6-\mathrm{mm}$ annular defects. Thomé et al.(9) reported that in patients with a large annular defect 
turkishspine

Table 3. Complications in patients with limited and aggressive discectomy

\begin{tabular}{|c|c|c|c|c|c|c|}
\hline \multicolumn{3}{|c|}{$\begin{array}{l}\text { Complications Sequestrectomy } \\
\text { Aggressive discectomy }\end{array}$} & \multicolumn{2}{|c|}{ Group } & \multirow{2}{*}{$\begin{array}{l}\text { Total } \\
124 \\
\end{array}$} & \multirow[t]{2}{*}{$\mathbf{p}$} \\
\hline \multirow{4}{*}{ Recurrence } & \multirow{2}{*}{-} & $\mathrm{n}$ & 60 & 64 & & \\
\hline & & $\%$ & $48.40 \%$ & $51.60 \%$ & $100.00 \%$ & \multirow{3}{*}{0.288} \\
\hline & \multirow{2}{*}{+} & $\mathrm{n}$ & 10 & 6 & 16 & \\
\hline & & $\%$ & $62.50 \%$ & $37.50 \%$ & $100.00 \%$ & \\
\hline \multirow{4}{*}{ Reoperation } & \multirow{2}{*}{-} & $\mathrm{n}$ & 62 & 64 & 126 & \multirow{4}{*}{0.573} \\
\hline & & $\%$ & $49.20 \%$ & $50.80 \%$ & $100.00 \%$ & \\
\hline & \multirow{2}{*}{+} & $\mathrm{n}$ & 8 & 6 & 14 & \\
\hline & & $\%$ & $57.10 \%$ & $42.90 \%$ & $100.00 \%$ & \\
\hline \multirow{4}{*}{ Infection } & \multirow{2}{*}{-} & $\mathrm{n}$ & 69 & 69 & 138 & \multirow{4}{*}{-} \\
\hline & & $\%$ & $50.00 \%$ & $50.00 \%$ & $100.00 \%$ & \\
\hline & \multirow{2}{*}{+} & $\mathrm{n}$ & 1 & 1 & 2 & \\
\hline & & $\%$ & $50.00 \%$ & $50.00 \%$ & $100.00 \%$ & \\
\hline \multirow{4}{*}{ Dural rupture } & \multirow{2}{*}{-} & $n$ & 66 & 68 & 134 & \multirow{6}{*}{0.404} \\
\hline & & $\%$ & $49.30 \%$ & $50.70 \%$ & $100.00 \%$ & \\
\hline & & $\mathrm{n}$ & 4 & 2 & 6 & \\
\hline & + & $\%$ & $66.70 \%$ & $33.30 \%$ & $100.00 \%$ & \\
\hline \multirow{2}{*}{\multicolumn{2}{|c|}{$\begin{array}{l}\text { Total } \\
\%\end{array}$}} & $\mathrm{n}$ & 70 & 70 & 140 & \\
\hline & & $50.00 \%$ & $50.00 \%$ & $100.00 \%$ & & \\
\hline
\end{tabular}

$\mathrm{n}$ : Number

Table 4. Surgical results and follow-up of patients with limited and aggressive discectomy

\begin{tabular}{llll} 
& & Group & p \\
\cline { 2 - 4 } & Sequestrectomy & Aggressive discectomy & 0.790 \\
\hline Blood loss & $45.21 \pm 8.05$ & $44.86 \pm 7.61$ & 0.420 \\
\hline Duration of surgery & $54.57 \pm 10.03$ & $55.93 \pm 9.72$ & 0.001 \\
\hline Amount of disc & $6.18 \pm 0.97$ & $12.33 \pm 1.68$ & 0.990 \\
\hline Length of hospitalisation & $1.27 \pm 0.72$ & $1.27 \pm 0.66$ & 0.040 \\
\hline Follow-up time & $2.26 \pm 0.47$ & $2.11 \pm 0.32$ & 0 \\
\hline
\end{tabular}

after limited microdiscectomy (LMD), the risk of symptomatic recurrence and reoperation was higher. In contrast to this study, the reoperation rate of the sequestrectomy group was higher (57.10\%), but without a statistical difference between the two groups, although the annular defect width was higher in the aggressive group $(p=0.573)$. In addition, recurrence rates were reportedly lower in patients with large annular defects repaired after microdiscectomy ${ }^{(9)}$. The regenerative capacity of the anulus fibrosus is very limited. Due to the intradiscal tension force, repair mechanisms of the annulus were also unsuccessful. Several strategies such as repair, regeneration and replacement of the herniated nucleus pulposus have not been clinically confirmed(15,16).
In this study, although hemilaminotomy and flavectomy were performed as standards in lumbar MC, the free fragment formed by the annulus fibrosus or posterior longitidunal ligament rupture in the spinal canal was resected in sequestrectomies; therefore, the disc distance was maintained and the back wall of the ligament and the annulus were preserved. However, most patients also had segmental disc segments at the intervertebral distance. These residual disc fragments have also been observed to migrate from the annular defect and ligament rupture into the spinal canal due to intradiscal tension. The free fragment, subligamentous sequester and degenerated disc fragments at the intervertebral distance were resected and the anterior longitudinal ligament was detected. Fragments located in the 
middle line or at opposite side of the disc interspace were also resected. Although blood loss $(p=0.790)$, surgical duration $(p=0.420)$ and length of hospitalisation were equal $(p=0.990)$ in both groups, the difference in the amount of disc resected during surgery $(p<0.05)$ and in the length of hospitalisation was statistically significant $(p<0.01)$. Complications such as recurrence and reoperation rates and dural tear were also higher in the limited discectomy group. Schmid et al.(17) reported that the clinical results and reoperation rates were equal in both the sequestrectomy and total discectomy groups.

In the literature, the incidence of dural tear is $1.8-2.7 \%$ in LMD and $3-5.7 \%$ in open discectomy ${ }^{(11,18-20)}$. In this study, although the dural tear was observed to be more common in the sequestrectomy group, no statistically significant difference was observed between the two groups in terms of the dural tear frequency. Although wound infection rate was reported as $3.3 \%$ in patients with sequestrectomy ${ }^{(20)}$, equal and lower rates (1.4\%) were observed in both groups in this study. Although the hospitalisation duration was between 1 and $12^{(21-23)}$ days, it was the same in the limited discectomy (1.27 \pm 0.72 days) and $A D$ groups (1.27 \pm 0.66 days), without statistical difference $(p=0.990)$. In a study conducted by Schick and Elhabony ${ }^{(15)}$, the patient group who underwent LMD with sequestrectomy was reported to have better duration of hospitalisation and postoperative VAS results in one group; however, return to daily activities, rate of labour loss due to low back pain and recurrence rates were equal.

Schmid et al.(17) investigated 500 patients with and without a surgical microscope and reported that reoperation and complication rates were equal in two groups, the surgical duration was longer in the microscope group and the length of hospitalisation was longer in the non-microscope group ${ }^{(22)}$. In addition, the surgical duration is expected to be longer in the $A D$ group because it involves entering the intervertebral distance and attempting to resect the residual discs located at a disc interdistance. Minimally invasive procedures have been increasingly performed in recent years. Grasso et al.(12) reported that when an LMD and a radiofrequency system were used together, the reherniation rate was lower, and analgesic use, compliance with social life and other results were better than that of the LMD (sequestrectomy) only group.

\section{CONCLUSION}

Although many noninvasive procedures have been defined as an alternative to $\mathrm{MC}$, surgical discectomy remains an effective treatment method for $\mathrm{LDH}$. We suggest that $A D$ should be preferred over other surgical methods due to its lower recurrence.

\section{Ethics}

Ethics: Since this study was written as a retrospective study before 2020, and patient records were used in this study, ethics committee approval was not obtained.
Informed Consent: Before the procedure, consent forms were obtained from the patients.

Peer-review: Externally peer-reviewed.

\section{Authorship Contributions}

Surgical and Medical Practices: F.A., Concept: F.A., F.Ş., Design: F.A., F.Ş., Data Collection or Processing: Y.P., Analysis or Interpretation: Y.P., Literature Search: F.A., F.Ş., Writing: F.A.

Conflict of Interest: No conflict of interest was declared by the authors.

Financial Disclosure: The authors declared that this study received no financial support.

\section{REFERENCES}

1. Mixter W], Barr JS. Rupture of the intervertebral disc with involvement of the spinal canal. N Engl J Med. 1934;211:210-5.

2. O'Connell JE. Protrusions of the lumbar intervertebral discs, a clinical review based on five hundredcases treated by excision of the protrusion. J Bone Joint Surg Br. 1951;33-B:8-30.

3. Schaller B. Failed back surgery syndrome: the role of symptomatic segmental single-level instability after lumbar microdiscectomy. Eur Spine J. 2004;13:193-8.

4. Williams RW. Microlumbar Discectomy: A Conservative Surgical Approach to the Virgin Herniated Lumbar Disc. Spine (Phila Pa 1976). 1978;3:175-82.

5. Spengler DM. Lumbar discectomy. Results with limited disc excision and selective foraminotomy. Spine (Phila Pa 1976). 1982;7:604-7.

6. Deyo RA, Tsui-Wu YJ. Descriptive epidemiology of low-back pain and its related medical care in theUnited States. Spine (Phila Pa 1976). 1987; 12:264-8.

7. Rhee JM, Schaufele M, Abdu WA. Radiculopathy and the Herniated Lumbar Disc. Controversies Regarding Pathophysiology and Management. J Bone Joint Surg Am. 2006;88:2070-80.

8. Carragee EJ, Spinnickie AO, Alamin TF, Paragioudakis S. A prospective controlled study of limited versus subtotal posterior discectomy: Short-term outcomes in patients with herniated lumbar intervertebral discs and large posterior anular defect. Spine (Phila Pa 1976). 2006;31:653-7.

9. Thomé C, Barth M, Scharf J, Schmiedek P. Outcome after lumbar sequestrectomy compared with microdiscectomy: A prospective randomized study. J Neurosurg Spine. 2005;2:271-8.

10. Watters WC, McGirt MJ. An evidence-based review of the literature on the consequences of conservative versus aggressive discectomy for the treatment of primary disc herniation with radiculopathy. Spine J. 2009;9:240-57.

11. Weinstein JN, Lurie J, Tosteson TD, Tosteson ANA, Blood EA, Abdu $W A$, et al. Surgical versus nonoperative treatment for lumbar disc herniation: four-year results for the Spine Patient Outcomes Research Trial (SPORT). Spine (Phila Pa 1976). 2008;33:2789-800.

12. Grasso G, Torregrossa F, Landi A. Prevention of lumbar reherniation by the intraoperative use of a radiofrequency bipolar device: A casecontrol study. J Craniovertebr Junction Spine. 2019;10:94-9.

13. Ran J, Hu Y, Zheng Z, Zhu T, Zheng H, Jing Y, et al. Comparison of discectomy versus sequestrectomy in lumbar disc herniation: A metaanalysis of comparative studies. PLoS One. 2015;10:e0121816.

14. Fakouri B, Patel V, Bayley E, Srinivas S. Lumbar microdiscectomy versus sequesterectomy/free fragmentectomy: A long-term ( $>2$ y) retrospective study of the clinical outcome. J Spinal Disord Tech. 2011;24:6-10.

15. Schick U, Elhabony R. Prospective comparative study of lumbar sequestrectomy and microdiscectomy. Minim Invasive Neurosurg. 2009;52:180-5.

16. Alvi MA, Kerezoudis P, Wahood W, Goyal A, Bydon M. Operative approaches for lumbar disc herniation: a systematic review and 
turkishspine

multiple treatment metaanalysis of conventional and mi imally invasive surgeries. World Neurosurg. 2018;114:391-407.e2.

17. Schmid SL, Wechsler C, Farshad M, Antoniadis A, Ulrich NH, Min K, et al. Surgery for lumbar disc herniation: Analysis of 500 consecutive patients treated in an interdisciplinary spine centre. J Clin Neurosci. 2016;27:40-3.

18. Righesso O, Falavigna A, Avanzi O. Comparison of open discectomy with microendoscopic discectomy in lumbar disc herniations: results of a randomized controlled trial. Neurosurgery. 2007;61:545-9.

19. Stolke D, Sollmann W, Seifert V. Intra- and postoperative complications inlumbar disc surgery. Spine (Phila Pa 1976). 1989;14:56-9.

20. Teli M, Lovi A, Brayda-Bruno M, Zagra A, Corriero A, Guidici F, et al. Higher risk of dural tears and recurrent herniation with lumbar microendoscopic discectomy. Eur Spine J. 2010;19:443-50.
21. Jacobs WC, Arts M, van Tulder MW, Rubinstein RM, Middelkoop MV Ostelo RW, et al. Surgical techniques for sciatica due to herniated disc, a systematic review. Eur Spine J. 2012;21:2232-51.

22. Türeyen K. One-level one-sided lumbar disc surgery with and without microscopic assistance: 1-year outcome in 114 consecutive patients. J Neurosurg. 2003;99:247-50.

23. Katayama $Y$, Matsuyama $Y$, Yoshihara $H$, Sakai $Y$, Nakamura $H$, Nakashima S, et al. Comparison of surgical outcomes between macro discectomy and micro discectomy for lumbar disc herniation: a prospective randomized study with surgery performed by the same spine surgeon. J Spinal Disord Tech. 2006;19:344-7. 